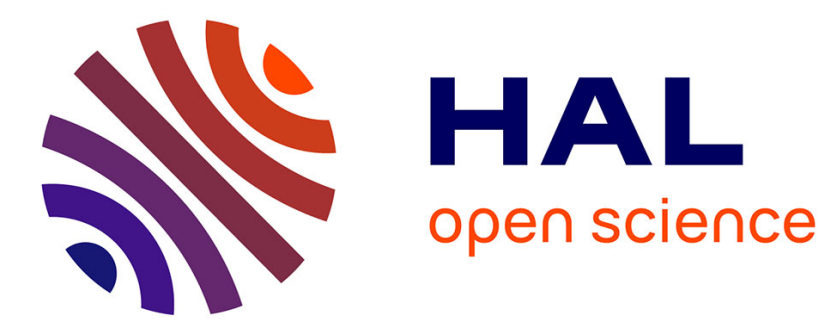

\title{
FAR AWAY FROM A SKILL-BIASED CHANGE: FALLING EDUCATIONAL WAGE PREMIA IN ITALY
}

Paolo Naticchioni, Andrea Ricci, Emiliano Rustichelli

\section{To cite this version:}

Paolo Naticchioni, Andrea Ricci, Emiliano Rustichelli. FAR AWAY FROM A SKILL-BIASED CHANGE: FALLING EDUCATIONAL WAGE PREMIA IN ITALY. Applied Economics, 2009, 42 (26), pp.3383. 10.1080/00036840802112455 . hal-00582248

\section{HAL Id: hal-00582248 \\ https://hal.science/hal-00582248}

Submitted on 1 Apr 2011

HAL is a multi-disciplinary open access archive for the deposit and dissemination of scientific research documents, whether they are published or not. The documents may come from teaching and research institutions in France or abroad, or from public or private research centers.
L'archive ouverte pluridisciplinaire HAL, est destinée au dépôt et à la diffusion de documents scientifiques de niveau recherche, publiés ou non, émanant des établissements d'enseignement et de recherche français ou étrangers, des laboratoires publics ou privés. 


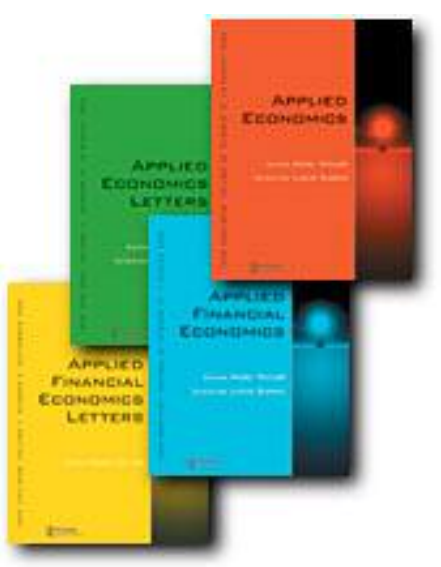

FAR AWAY FROM A SKILL-BIASED CHANGE: FALLING EDUCATIONAL WAGE PREMIA IN ITALY

\begin{tabular}{|c|c|}
\hline Journal: & Applied Economics \\
\hline Manuscript ID: & APE-07-0398.R1 \\
\hline Journal Selection: & Applied Economics \\
\hline $\begin{array}{r}\text { Date Submitted by the } \\
\text { Author: }\end{array}$ & 07-Feb-2008 \\
\hline Complete List of Authors: & $\begin{array}{l}\text { Naticchioni, Paolo; Università La Sapienza, Dipartimento di Scienze } \\
\text { Economiche } \\
\text { Ricci, Andrea; University of Perugia, Dipartimento di Economia, } \\
\text { Finanza e Statistica } \\
\text { Rustichelli, Emiliano; ISFOL }\end{array}$ \\
\hline JEL Code: & $\begin{array}{l}\text { J24 - Human Capital|Skills|Occupational Choice|Labor Productivity } \\
<\text { J2 - Time Allocation, Work Behavior, and Employment } \\
\text { Determination/Creation < J - Labor and Demographic Economics, } \\
\text { J31 - Wage Level, Structure; Differentials by Skill, Occupation, etc. } \\
<\text { J3 - Wages, Compensation, and Labor Costs < J - Labor and } \\
\text { Demographic Economics }\end{array}$ \\
\hline Keywords: & $\begin{array}{l}\text { Educational wage premia, Returns to education, Quantile } \\
\text { regression, Italy }\end{array}$ \\
\hline
\end{tabular}

\section{(5) ScholarONE \\ Manuscript Central}




\title{
FAR AWAY FROM A SKILL-BIASED CHANGE: FALLING EDUCATIONAL WAGE PREMIA IN ITALY
}

\author{
Paolo Naticchioni \\ University of Rome "La Sapienza", Univ. Catholique de Louvain \\ Andrea Ricci \\ University of Perugia \\ Emiliano Rustichelli \\ ISFOL
}

January 2008

\begin{abstract}
In this paper we apply quantile regressions to investigate the evolution of Educational Wage Premia (EWP) in Italy from 1993 to 2004. Using the Survey of the Household Income and Wealth (SHIW - Bank of Italy) and different classifications for educational attainments, we show that in the private sector EWP have generally decreased over time, considering both continuous and categorical specifications for education, at all quantiles of the wage distribution. Different patterns are observed in the public sector, where EWP remain basically stable over time. A number of robustness checks and various econometric specifications are also applied in order to address sample selection issues. Our findings provide additional evidence in favour of the thesis that the increasing patterns in inequality and EWP, and the related interpretations concerning skill-biased changes, are much less pronounced in continental Europe than in Anglo Saxon countries.
\end{abstract}

JEL codes: I20, J24, J31,

Keywords: Educational wage premia, Returns to education, Quantile regression, Italy. 


\section{Introduction}

The analysis of educational wage premia (EWP) is a traditional topic in labour economics as it provides a statistical relationship between educational attainments and the structure of wage distribution. Empirical interest in EWP has actually increased over the last decades since the spread of new technologies is believed to favour skilled workers, entailing an increase in wage inequality between (and within) individuals characterized by different endowments of human capital.

Taking reference from this literature, our paper aims at investigating the evolution of EWP across the wage distribution in Italy in the private sector. An analysis is also carried out on the public sector for the sake of comparison. The changes in EWP are estimated by applying quantile regressions and using the Survey of the Household Income and Wealth (SHIW) of the Bank of Italy, from 1993 to 2004. As for education, we make use of both a categorical specification (primary, lower secondary, upper secondary and tertiary) and a continuous one (years of education). Applying quantile regressions offers some remarkable advantages with respect to standard procedures regarding the conditional mean. First, since the effect of education may vary across individuals situated at different points of the earnings distribution, using a quantile approach allows for the detection of heterogeneity among the educational premia. In such a way we can characterize in general terms the functional relationship between education and unobserved abilities (Koenker and Basset, 1982). Second, under the assumption that such a functional relationship between education and unobserved abilities is time invariant, the inter-temporal comparison of EWP estimates is not affected by omitted variable biases, at all quantiles.

Within this framework, the main result of our analysis is that EWP in the private sector decreased over the period and across the whole wage distribution. Actually, EWP remained stable between 1993 and 1995, while they started a decreasing trend as from 1998, and the fall in EWP grew greater over time. Focusing on the difference between 1993 and 2004, and using the Mincerian continuous specification for education, EWP decrease at all quantiles, from $40.8 \%$ at the $10^{\text {th }}$ percentile to $13.1 \%$ at the $90^{\text {th }}$ percentile. When education is measured in dummies (the omitted category being primary education), the decline in EWP of lower secondary degrees is significant (between $-50 \%$ and $-60 \%)$ in the upper tail of the distribution, that of upper secondary premia ranges between $29.5 \%$ and $40.1 \%$, and the EWP for tertiary education decrease from $-35.4 \%$ at the $10^{\text {th }}$ percentile to $-17.2 \%$ at the $90^{\text {th }}$. Further, OLS estimates confirm the findings derived using quantile regressions, applying both continuous and categorical specification.

Similar patterns are derived when the estimates are replicated using more detailed information concerning different types of high school (general, 
vocational) and tertiary degree achievements (humanistic, professional, scientific), highlighting the fact that previous results are not driven by composition effect related to the type of schooling levels. In particular, EWP for both vocational and general high school individuals decrease over time in a similar way. As for tertiary education, humanistic and professional degrees are associated with falling EWP, while EWP for scientific degrees decrease but in a non significant way.

This evidence also holds when a wide set of robustness checks are performed to tackle sample selection issues. More specifically, we estimate the EWP for different sub-samples of workers (male full time, including self-employed, young vs. adults) in order to test whether changes in labour market participation decisions could have affected the estimates. In an additional robustness check we make use of a more general specification of the wage equation, adding a wide set of covariates to the standard Mincerian approach.

These robustness checks do not necessarily address all the econometric issues related to estimation of the returns to education, and, in particular, those associated with the endogeneity of schooling choices. ${ }^{1}$ To handle the resulting biases a number of empirical strategies have been proposed in the literature. Among these, the instrumental variable techniques based on both natural experiments and exogenous variations, and the approach of exploiting the differences between siblings or twins, have received a great deal of attention. Some previous papers on returns to education in Italy derived convincing instrumental variables in the SHIW data, exploiting information provided by the school reforms of the 1960s (Brunello et al., 1999). However, this type of instrumental variables becomes much less convincing when the focus of the analysis is the time dynamics of EWP. In fact, since the effects of school reforms change according to the population sub-group involved in the reforms, the group of compliers affected by the instruments changes over time, affecting in turn dynamic comparison of the estimates. ${ }^{2}$ For this reason, and since our primary goal is to focus on the evolution of the statistical relationship between educational premia and the structure of the wage distribution, the issue of schooling endogeneity is not further investigated.

It is also worth pointing out that our findings for the private sector are not in line with the international empirical evidence, especially in the case of the

\footnotetext{
1 Peracchi (2006) distinguishes between returns to education, which is a measure of the causal effect of an extra level of schooling on the worker's earnings, and educational wage premia, which is a measure of statistical association between levels of schooling and wages. We make use of this terminology in the paper.

2 For a detailed explanation on how IV-LATE estimates can change using different instruments and different groups of compliers, see Angrist et al. (1996). Furthermore, as also stressed by Peracchi (2006), IV estimates of returns to education usually exceed OLS estimates, even though they also tend to be less precise, possibly because of a weak instrument problem. See also Ashenfelter, O., C. Harmon and H. Oosterbeek (1999).
} 
Anglo-Saxon countries, where the role of EWP is considered as the driving force of both increasing inequality and skill-biased changes. Instead, we provide additional evidence that phenomena related to skill-biased change seem to be much less pronounced in continental Europe. Furthermore, even with respect to the evidence for European countries, which usually shows stable or slightly increasing EWP, the Italian case is peculiar because EWP decrease for all education attainments across the whole wage distribution, the only comparable case being that of Austria (Fersterer and Winter-Ebmer, 1999).

As for the public sector, we find quite different patterns emerging: EWP remain basically stable over time. These findings may be due to institutional features of the public sector, such as greater union power (Borland and Gregory, 1999), and various reforms on the wage setting system introduced in this sector in 1993 and 1998 (Dell'Aringa et al., 2007). Future research is needed to investigate further the driving forces behind the patterns observed in the private and public sector. ${ }^{3}$

The remainder of the paper is organized as follows. Section 2 reviews the empirical literature on educational premia. Section 3 describes the database and some descriptive statistics, while the quantile regression methodology is presented in Section 4 . In section 5 we set out our estimates for both the private and the public sector, while sections 6 reports some robustness checks. Section 7 draws the conclusions.

\section{The empirical literature}

The time trends of EWP reveal quite different patterns across countries, since differences in educational systems, income measures, data collection procedures and estimation strategies substantially affect the magnitudes of the estimates and the cross-country comparisons (Gottschalk and Smeeding, 1997; Peracchi, 2006). For this reason, in this survey we focus mainly on the dynamic pattern of educational premia derived in country specific studies.

As for the US, several papers have shown considerable increases in earning differentials both between workers with different schooling levels and within workers with the same observable characteristics. More specifically, tertiary wage premia showed a marked decline during the 1970s, increased substantially during the 1980s and rose with a smoother trend in the 1990s (Bound, and Johnson, 1992; Juhn, Murphy and Pierce, 1993; Card, 2001). Most of these results, however, regard the central tendency of the earning data, ruling out any concern about the heterogeneous impact of education along the wage distribution. One of the first exceptions is Buchinsky (1994), who makes use of

\footnotetext{
${ }^{3}$ See Naticchioni and Ricci (2008), who carry out an analysis of the effects of the dynamics of EWP on inequality trends in Italy, in both the private and the public sector.
} 
quantile regressions to investigate the changes in the structure of US wages during the ' $80 \mathrm{~s}$ and '90s, i.e., to measure the effect of schooling at different quantiles of the conditional earning distribution. Buchinsky (1994) underlines two main findings. First, acquiring an additional educational qualification increases the wage at all quantiles of the distributions, with a stronger effect in the upper tail of the distribution. Second, returns increased over time at all quantiles at approximately the same rate. A similar pattern is found by Martins and Pereira (2004), who estimate the educational premia for 16 European countries during the '90s. By applying quantile regressions these authors show that EWP are generally higher at the highest quantiles of the conditional wage distribution in almost all the countries considered, although no thorough investigation is made into the dynamic pattern of these estimates.

Other interesting country specific studies for Europe, that make use of quantile regressions, are Fitzenberger and Kurz (2003) for Germany, Machado and Mata (2001) for Portugal, and Fersterer and Winter-Ebmer (1999) for Austria. In particular, Fitzenberger and Kurz (2003) show that education has a greater effect on the wages of individuals at the top of the wage distribution than on those at the bottom. Using pooled data for Germany in the period 19841994, they report that the college premium -over the high school- amounts to $32 \%$ at the $10^{\text {th }}$ percentile and $41 \%$ at the $90^{\text {th }}$, although there are no significant changes in these estimates over the period.

In Portugal, Machado and Mata (2001) use quantile regressions to describe the evolution of the conditional wage distribution between 1982 and 1994 . Much as in the German case, they point out that EWP increase along the quantile distribution in each sample year. Further, they show that while the median returns are roughly constant, the impact of education at the two tails of the distribution follows opposite patterns: the EWP at the lowest quantiles decreased by $1.5 \%$ while the EWP at the $90^{\text {th }}$ increased by $3 \% .{ }^{4}$ As for Austria, the paper by Fersterer and Winter-Ebmer (1999) shows that schooling premia fell over the period 1981-1997, a result in contrast with evidence from other developed countries, and which the authors attribute to the increase in the relative supply of more educated workers in the last two decades. ${ }^{5}$

As far as Italy is concerned, some papers estimated the average returns to schooling by applying least square or instrumental variables techniques (Brunello and Miniaci, 1999; Brunello, Comi and Lucifora 2001). For instance, Brunello and Miniaci (1999) use SHIW (Bank of Italy) data for 1993 and 1995 to measure the returns to schooling, obtaining an OLS estimate of $4.8 \%$ and an IV estimate, which exploits a reform in the school system introduced in 1969, of

\footnotetext{
${ }^{4}$ For another analysis concerning the Portugal case see Hartog, Pereira, Vieira (2001)

${ }^{5}$ For analysis concerning other countries see: Magoula and Psacharopoulos (1999) for Greece, Palme and Wright (1998) for Sweden.
} 
$5.7 \%$ for male head of households. Similar findings are derived by Brunello, Comi and Lucifora (2001), who develop their analysis on the same dataset and use as instruments some variables related to family background, school system reforms and measures of individual risk aversion. They also detect an increasing trend of EWP from 1977 to 1995, which was mainly driven by higher EWP in the public sector.

However, these studies emphasise the causal interpretation of schooling investments, although they do not take into account the relationship between schooling premia and the whole wage distribution. This issue is investigated by Giustinelli (2004), who apply quantile regressions to investigate the dynamic of EWP over the period 1993-2000 using SHIW data. The main result is that the schooling premium shows a $U$ shaped pattern across the wage distribution in each sample year, while the trend over time of EWP is not deeply investigated. Another related paper is Lilla (2005), which estimates educational wage premia up to the year 2002, using SHIW data and quantile regressions. However, Lilla (2005) mainly investigates the within-between components of wage inequality in Italy, without deeply focusing on the trends in educational wage premia.

It is also important to stress that the low levels of educational attainments of the workforce represent another distinctive characteristic of the Italian labour market. According to OECD (2006), the share of individuals who had achieved a tertiary degree in 2004 stood at $11 \%$ in Italy, as compared with $24 \%$ in France, $25 \%$ in Germany, 29\% in the UK, and 39\% in the US. Moreover, the catch-up process is slowing down, since the tertiary enrolment rate in absolute terms decreased in $2004-2005$ by $1.5 \%$ and in $2005-2006$ by $4.5 \%$. Such a slowdown is also confirmed by looking at the individuals aged 25-34: the rate of graduates in this age-class differs little from the previous figures: 15\% in Italy, 24\% in France, $23 \%$ in Germany, 35\% in the UK and 39\% in the US. On this evidence Italy displays among the lowest educational attainments among the OECD countries, while the catching up process is converging at a very slow rate.

These striking international differences might suggest that since highly educated workers are relatively scarce in Italy, their wage premia should be relatively higher, according to a standard demand-supply paradigm. However, this is by no means the case. The OECD (2005) states that the tertiary education premia in Italy are lower than in the other OECD countries. More specifically, with respect to secondary education (at 100), the premium for having a tertiary education degree for individuals aged between 30 and 44 is 137 in Italy, 150 in France, 163 in UK and 185 in the US (OECD, 2005). This means that EWP levels seem to be lower in Italy than in most of the OECD countries. What about the EWP evolution over time? This paper mainly addresses this issue in a quantile regression framework for the period 1993-2004. 
3. Data description and descriptive statistics

The empirical analysis is based on the Survey of the Household Income and Wealth (SHIW) of the Bank of Italy, from 1993 to 2004. The sample consists of employees aged 15-64. We refer to the real monthly net wage, obtained by dividing yearly income from employment, net of taxes and social security contributions, by the number of months worked in the relevant year and deflating by the consumer price index of 2004. We also use both part time and full time workers, correcting the monthly wage for part-timers with a part-time share, computed comparing the number of hours worked by part-timers with the average for the full-time workers. ${ }^{6}$

Table 1 gives the descriptive statistics of the main variables in 1993 and 2004 for both the private and the public sector. ${ }^{7}$ Focusing on the pattern of educational dummies it can be observed that, for both sectors, the shares of individuals with upper secondary and tertiary attainments increased over time, while the shares of individuals with primary and lower secondary education declined. Further, a higher share of graduated workers are employed in the public sector (in 2004, 27.5\% of the employees in the public sector were graduated, and only $8.7 \%$ in the private one), even if differences between the two sectors are getting closer over time.

As for the experience variable, it is defined as the difference between the current age of the worker and the age of that worker at the beginning of his/her labour career, and it is classified in eight categorical dummies. ${ }^{8}$ Table 1 shows that there is a falling incidence of employees with less than 15 years of experience and an increasing share of those with more than 16 years. Similarly, in the public sector the share of individuals with less than 25 years of experience decreased substantially, and the one of those with more than 25 years rose, involving an increase in the level of experience in the workforce. As for the share of female workers, it is higher in the public sector and it rose steadily in both sectors, a trend linked to the higher labour force participation of women in

${ }^{6}$ Note also that we exclude $0.05 \%$ of the observations in both the right and left tail.

${ }^{7}$ We define a public employee using two variables in the database, APSETT and DIMAZ. APSETT provides us with self-declaration of the sector in which the individual works, including the public sector, while DIMAZ refers to the firm size, and it is specified when the employee declares that he/she is employed in the public sector. We consider as public employees those workers who declare for both questions that they are employed in the public sector. Results do not change much when we consider definitions of public employee based on APSETT and DIMAZ separately.

${ }^{8}$ We also used different definitions for experience. For instance, in order to take into account individuals working during their scholastic carrier, we also defined the experience variable as: (age-years of formal education-6). More specifically, we use this modified experience measure when it is lower than the measure used in the paper; otherwise, we continue using the measure in the paper. However, since in Italy the practice of working during the university period is much less developed than in other European countries, this measure for experience is very highly correlated with the one used in the paper (0.99). For this reason, EWP do not change using this different measure for experience. 
the last decades. With regard to the wage changes, Table 1 shows that from 1993 to 2004 the average monthly wage, in real term, remained basically stable both in the private and public sector. Further, wages are higher in the public sector than in the private one.

We also generate a finer classification of education attainments, in order to isolate different kinds of upper secondary schools and tertiary degrees. This finer classification is useful to investigate whether the EWP dynamics derived with educational classification in 4 dummies might partially depend on composition effects related to different groups included in each dummy. In particular, we create a dummy for general upper secondary degrees ('liceo') and another one for all the other vocational upper secondary degrees (including also individuals that achieve short upper secondary degrees, usually in three years). As for tertiary education, we define three categories: humanistic degrees (including humanities, social science and sociology); professional degrees (law, economics, accounting, architecture), and scientific degrees (physics, mathematics, medicine, engineering). ${ }^{9}$ Unfortunately, since for 1993 this information was not included in the SHIW data, we have to use the SHIW survey of 1995. In table 2 we set out the related descriptive statistics, for subordinate workers aged 15-64, separately for private and public sector. As for the upper secondary levels, while the general school (liceo) share increased over time, it was the vocational schools that still attracted most of the students (around $88 \%$ in 2004 in the private sector). As far as tertiary education is concerned, the public sector absorbs a higher share of workers with humanist degrees, while the private sector is more focused on professional and scientific degrees. Further, in the private sector the share of humanist degrees increased over time, while professionals displayed a quite impressive reduction from $37.9 \%$ to $29.2 \%$, as well as the share of workers with a scientific degree, even if more slightly. Different patterns are observed in the public sector, where the share of individuals with humanistic and professionals degrees decreased slightly, while the scientific ones increased over time.

\section{The quantile regression framework}

This section presents the quantile regressions methodology, used in the paper. In general terms, let $Q_{\theta}\left(y_{i, t} \mid X_{i, t}\right)$ be the conditional $\theta$-th quantiles of the dependent variable on the explanatory variables $X_{i, t}$. The statistical model $Q_{\theta}\left(y_{i, t} \mid X_{i, t}\right)$ is specified as a linear function of the covariates:

$$
y_{i}=X_{i} \beta_{\theta}+v_{\theta i} \quad \text { with } Q_{\theta}\left(y_{i} \mid X_{i}\right)=X_{i} \beta_{\theta}, \quad \theta \in(0,1)
$$

\footnotetext{
9 We cannot consider all the other less widespread kinds of tertiary degrees $(10 \%$ of the graduates in the sample), since the SHIW database put them in the same category, without any distinction. We drop these observations from this kind of analysis.
} 
where the vector of coefficients $\beta_{\theta}$ varies with $\theta$, unless the conditional distribution of $y$ is homoskedastic, in which case only the intercept included into the vector $\beta_{\theta}$ varies across quantiles. Further, in equation (1) it is assumed that the error term, $v_{i, t}$ is such that $Q_{\theta}\left(v_{\theta_{i}} \mid X_{i, t}\right)=0 .{ }^{10}$ Using the statistical framework (1) we adopt a linear specification of the wage function of the type introduced by Mincer (1974), where the dependent variable is the log monthly wage and the independent variables include educational attainments, work experience and gender. The following equation is then estimated, separately for 1993 and 2004:

$$
\ln w_{i, t}=\alpha_{\theta, t}+\eta_{\theta, t} \operatorname{sex}_{i, t}+\delta_{\theta, t} \cdot e d u c_{i, t}+\mu_{\theta, t} \exp _{i, t}+v_{\theta, i, t} \quad \mathbf{t}=1993,2004,
$$

where $i=1, \ldots \mathrm{N}$ is the number of observations in each year $t, \theta$ is the quantile being analysed, sex stands for gender, educ is a measure of educational attainments, $\exp$ stands for experience and $\alpha_{\theta, t}, \eta_{\theta, t}, \delta_{\theta, t}, \mu_{\theta, t}$, are the coefficients to be estimated for each year and at the chosen quantiles.

Since the focus of our analysis is on the dynamic patterns of EWP, equation (2) does not explicitly take into account the functional relationship between unobserved ability and schooling levels, nor the effect of their interaction on the conditional distribution of (log) wages. To explain this point better, equation (2) can be generalized as follows:

(3) $\ln w_{i, t}=\alpha_{\theta, t}+\eta_{\theta, t} \operatorname{sex}_{i, t}+\delta_{\theta, t} \cdot e d u c_{i, t}+\mu_{\theta, t} \exp _{i, t}+\Phi\left(e d u c_{i, t}, a_{i, t}\right)+v_{\theta, i, t}$

where the unknown function $\Phi$ represents the education-ability interaction, $a_{i}$ stands for the unobserved ability, while the idiosyncratic error term, $v_{\theta, i, t}$, is such that $Q_{\theta}\left(v_{\theta, i, t} \mid X_{i}\right)=0$. According to Card (2001), it is possible to impose a parameterization of the function $\Phi$ to derive a monotonic impact of ability across the wage distribution when $e d u c_{i}$ varies. In such a context, if we assume that $\Phi\left(e d u c_{i, t}, a_{i, t}\right)=\sigma \cdot e d u c_{i, t} a_{i, t}$, where $\sigma$ is a parameter which captures the effect of ability on education returns, the EWP on the $\theta$ th conditional quantiles can be written as: ${ }^{11}$

$$
\begin{array}{r}
\frac{\partial Q_{\theta}\left[\ln w_{i, t} \mid e d u c_{i, t}, \operatorname{sex}_{i, t}, \exp _{i, t}\right]}{\partial e d u c_{i, t}}=\delta_{\theta, t}+\sigma \cdot Q_{\theta}\left(a_{i, t} \mid e d u c_{i, t}, \operatorname{sex}_{i, t}, \exp _{i, t}\right) \\
=\delta_{\theta, t}+\sigma \cdot G_{a}^{-1}\left(a_{i, t} \mid e d u c_{i, t}, \operatorname{sex}_{i, t}, \exp _{i, t}\right) \equiv \delta_{\theta, t}^{\prime}
\end{array}
$$

where $\delta_{\theta, t}^{\prime}$ is the quantile treatment effect due to changes in schooling attainments at each $\theta$ and $Q_{\theta}(a \mid \cdot)$ is the conditional quantile of the ability distribution, and $G_{a}{ }^{-1}$

${ }^{10}$ For further discussion on methodological grounds and techniques used to perform point and interval inference see Koenker and Basset (1978) and Buchinsky (1994).

${ }^{11}$ For further a more general specification of the function $\Phi$ see Arias, Hallock and SosaEscudero, 2001. 
is the conditional ability distribution in the population. ${ }^{12}$ The impact of education on wages, as formalized in equation (4), reflects the distribution of individual ability across the earnings distribution, underlining the fact that the general specification of equation (3) is not a pure location model and that the slope of coefficients varies across quantiles. In particular, by verifying that the estimated coefficients $\delta_{\theta, t}^{\prime}$ differs across quantiles we can characterize the functional relationship between education and unobserved abilities in general terms (Koenker and Basset, 1982).13 Hence, the main difference between cross sectional estimates of EWP derived from equation (3) and those that would be obtained from the estimation of equation (2) regards the differentiated effect of unobserved ability across quantiles of the wage distribution.

However, since our analysis is focused on dynamic trends in EWP, estimating wage equation (2) does not affect the validity of our results if the distribution of individual ability is supposed time invariant. Actually, by comparing the quantile treatment effect in two sample years, $t_{0}$ and $t_{1}$ with $t_{0}<t_{1}$, and assuming that the distribution of the conditional quantile of ability, $Q_{\theta}(a \mid \cdot)$, is time invariant, the dynamic pattern of the educational premia corresponding to the $\theta^{\text {th }}$ quantile is equal to the difference $\delta_{\theta, t_{1}}-\delta_{\theta, t_{0}}$, i.e. the quantile treatment effect of education between two different time periods does not depend on the ability bias. ${ }^{14}$

The hypothesis that distribution of abilities in the population is time invariant might be questionable if the skill formation of different cohorts of individuals in the sample between 1993 and 2004 had been affected by the schooling reforms of the early 1960s. Actually, Heckman et al. (2006) argue that ability differences between individuals begin to open up at early ages for both cognitive and non-cognitive skills. This means that a vast array of abilities that influence wages during adults' life cycles are produced by environment, investment and genes at early stages of childhood. In particular, the returns on early educational investment are higher than returns on late educational investment during child development because of dynamic complementary, self-

\footnotetext{
12 In particular, by applying the probability integral transformation theorem to the conditional quantiles of the ability distribution, i.e. $Q_{\theta}\left(a_{i, t} \mid e d u c_{i, t}, \operatorname{sex}_{i, t}, \exp _{i, t}\right)$, it is possible to make explicit in equation (4) the specific effect of unobserved ability for each selected quantiles, that is $G_{a}^{-1}\left(\theta \mid e d u c_{i, t}, \operatorname{sex}_{i, t}, \exp _{i, t}\right)$, where $G_{a}$ is some monotonic transformation of the ability distribution in the population.

${ }^{13}$ In a cross sectional analysis this represents an advantage in using quantile regressions rather than the OLS approach, which can only estimate an average treatment effect of education, i.e. the EWP for an individual with mean ability.

${ }^{14}$ Note also that the intertemporal comparison of OLS estimates of EWP would be unaffected by ability bias if it is assumed that the average ability in the population is time invariant. In this case, however, the results would hold only for the central tendency of the data and cannot be generalized to the dynamics of the whole wage distribution.
} 
productivity and multiplier effects in the technology of skill formation (Cuhna and Heckman, 2007). Referring to this literature, we may assume that the 1962 reform of the school system, which raised the compulsory educational level from primary to lower secondary school, did not significantly shift the distribution of abilities of the cohorts involved, as it regarded schooling investments of young adolescents and not of pupils at earlier stages of their childhood. This assumption is confirmed by the findings of Brandolini and Cipollone (2002), which show that the 1962 reform actually increased the average years of schooling and school attendance rates, although the effect on wages proved persistently positive and sizeable in magnitude only for the cohort of females directly affected by the reform. ${ }^{15}$ This means that the share of individuals for which the 1962 reform may have significantly changed abilities was about $9 \%$ in 1993 and 7\% in 2004 - shares low enough to justify the assumption that the distribution of ability be time invariant.

Moreover, inter-temporal comparisons of the estimates could also be affected by changes in labour market frictions. More specifically, the changes in the probability that a high (low) educated worker is particularly unlucky (lucky) in the matching process ending up with a poorly (well) paid job might play a role. However, under the plausible assumption that the distribution of unobserved ability is independent of "returns to luck" associated with labour market frictions, it is possible to rule out this concern. Actually, random matching of exante identical individuals in terms of educational attainments can generate frictional wage dispersion after the completion of schooling (Hornstein et al. 2005). On the other hand, unobserved abilities are mainly determined by genetic and environmental factors at early stages in childhood (as in Heckman et al. 2007), i.e., before an individual faces the random matching process in the labour market. Consequently, the patterns of EWP, as formalized by equation (4), can be assumed as independent from changes in returns to luck in the labour market.

\section{The dynamics of EWP in Italy: quantile estimates}

In this section we present the dynamics of EWP separately for the private and public sector, since these two sectors are supposed to differ from a structural point of view. In particular, Gregory and Borland (1999) make an international comparison among OECD countries, showing that the public sector is in general characterized by higher average wages, lower inequality, higher incidence of unions, and higher incidence of females. As for the Italian situation, few studies have gone into the differences between the two sectors. Dell' Aringa, Lucifora,

\footnotetext{
${ }^{15}$ In particular, only women born in the 1949-56 period experienced higher real wages than women belonging to the previous and following cohorts $(2.6 \%$ in comparison to the both $1932-$ 1948 and 1957-1967 cohorts).
} 
Origo (2007) provide descriptive statistics regarding the main differences between the two sectors, even if the focus of their paper is on the relation between public-private pay differentials and regional labour market conditions.

\subsection{Falling EWP in Italy in the private sector}

The empirical procedure consists in estimating two different specifications of equation (2) at five quantile regressions of the conditional (log) wage distribution, namely $\theta=.1,25, .5, .75, .9$, separately for the years 1993 and 2004. ${ }^{16}$ In the first specification, education is formalized through a continuous variable, namely years of schooling. ${ }^{17}$ In the second, education is expressed in four dummy variables for different schooling attainments (no-school and primary education, lower secondary, upper secondary and tertiary). In this latter case, we further extend the analysis to a finer classification of education categories in order to address issues related to the type of upper secondary schools and the quality of skills acquired with a tertiary degree. For each sample year, the estimation method consists of a simultaneous quantile regression, as standard tests reject the homoscedasticity hypothesis of the error terms. ${ }^{18}$

The first column of Table 3 sets out the EWP at selected quantiles for the year 1993 in the private sector, while the other columns show the variations between the coefficient for that given year $(1995,1998,2000,2002,2004)$ and the coefficient in 1993. In the last column in table 3 we also give the percentage variations occurring from 1993 to 2004.

In a cross sectional perspective, the estimated coefficients for years of schooling (continuous specification) show a convex pattern across quantiles of the wage distribution in 1993 and an increasing pattern along the distribution in 2004. ${ }^{19}$ The shape of the EWP is slightly different when education is measured

\footnotetext{
${ }^{16}$ We decided to begin our analysis in 1993 because in 1992-1993 the former wage indexation mechanism ('scala mobile') was replaced by a completely new bargaining system. Since then, the bargaining structure of the wage setting has not changed, and can be described as a two-tier system: national contracts are devoted to preserve the purchasing power of wages, whereas decentralised wage bargaining at firm level should be related to rent-sharing, in case of positive surplus.

17 Education in the continuous specification is computed attributing 5 years for elementary school attainment, 8 years for lower secondary school, 13 years for upper secondary school and 17 for more highly educated workers. Note also that our classification for education is consistent with the international classification ISCED.

18 In particular, we perform simultaneous quantile regressions obtaining an estimate of the variance-covariance matrix via bootstrapping. The standard errors are based on the heteroscedastic bootstrap methods where the sample size is equal to the number of observations each year. Further, to validate the heteroscedasticity hypothesis of the quantile regressions we successfully test that the coefficients estimated at different quantiles be statistically different from each other (Buchinsky, 1994, Koenker and Basset, 1978).

${ }^{19}$ Due to limits of space, we do not provide coefficients for all the years after 1993, but only variations. However, the coefficients can easily be computed from the level in 1993 and the variations over time.
} 
by dummies. In this case there is a positive relationship between the premia of tertiary education and quantiles of the wage distribution in 1993, varying from 0.73 at the $10^{\text {th }}$ percentile to 0.87 at the $90^{\text {th }}$. As far as wage premia for upper secondary are concerned, they display a convex shape across the distribution in 1993, while the lower secondary premia have irregular patterns in each year. Similar trends are observed for the years after 1993.

Although the broad picture emerging from cross sectional analysis does not change greatly from 1993 to 2004, the differences in the evolution over time of the estimates at different points of the distribution are remarkable (Table 3). In particular, when a continuous specification for schooling is adopted, the EWP are shown to be stable from 1993 to 1995, i.e. all variations are not statistically different from zero, while EWP begin to decrease in 1998, where the variations at all quantiles (except at the $90^{\text {th }}$ percentile) are negative and significant, as well as for variations in 2000 and 2002. Further, variations between 1993 and 2004 are always negative and significant, at all quantiles. More specifically, considering the percentage variations from 1993 to 2004 shown in the last column, the educational premia decreased by $40.8 \%$ at $10^{\text {th }}, 30.2 \%$ at the $25^{\text {th }}, 23.7 \%$ at the median, $20.5 \%$ at $75^{\text {th }}$ and by $13.1 \%$ at the $90^{\text {th }}$ percentile. ${ }^{20}$ The decline of EWP is, then, higher at the bottom of the distribution than at highest quantiles. ${ }^{21}$

A similar dynamics of EWP emerges also when education is classified in dummies, with the omitted category being no school or primary. In particular, variations from 1993 to 1995 are not statistically different from zero for all dummies, while they begin to become negative and significant in 1998 and in 2000 , especially at the $25^{\text {th }}, 50^{\text {th }}$, and $75^{\text {th }}$ percentiles, and finally they became more and more negative in 2002 and in 2004. More specifically, from 1993 to 2004 the observed decline concerning lower secondary education is around 50$60 \%$ and takes place in the upper tail of the distribution, while the fall for upper secondary range between $-40.1 \%$ at the $10^{\text {th }}$ to $-29.5 \%$ at the $90^{\text {th }} .22$ Interestingly

20 To test whether the variation over time of EWP coefficients is significant we assume that each coefficient is distributed normally and that the population in 2004 is independent from the 1993 population. This is quite plausible, since only $10 \%$ of the SHIW population in 2004 were also interviewed in 1993, in the panel component of the SHIW.

${ }^{21}$ It might be argued that carrying out two separate sets of regressions for 1993 and 2004 we cannot control for some aggregate omitted variables that could change over time, such as the business cycle. For this reason, we have also pooled the two years together, introducing interacted variables (the time dummy for 2004 times the dummies of lower secondary, upper secondary and tertiary education) along with our standard variables (gender, education, experience). In this framework, the variations in EWP are given by the coefficients of the interacted variables. In such a way, we can control for time dummies, which can considered as a proxy for unobserved aggregate omitted variables. The results do not change: the interacted terms are negative and significant for all educational attainments, while the time dummy is not significant, suggesting that the business cycle have not so different between 1993 and 2004 .

${ }^{22}$ Note that the share of individuals with an upper secondary degree increased in the private sector from $33 \%$ to $46 \%$, in the period 1993-2004. Hence, the falling EWP for this category might be explained using a demand-supply paradigm. 
enough, the university degree wage premia also decrease significantly over time at all the selected quantiles: the decline is equal to $35.6 \%$ at the $10^{\text {th }}, 29.3 \%$ at the $25^{\text {th }}, 25.7 \%$ at the median, $17.3 \%$ at the $75^{\text {th }}$ and $17.2 \%$ at the $90^{\text {th }}$ percentile. ${ }^{23}$ Even though the decline of EWP for graduates become lower at highest quantiles of the wage distribution, these findings contrast with most of the available empirical evidence on returns to education for other OECD countries. Figure 1a, 1b, 1c, and 1d display also the variations from 1993 to 2004 for EWP for lower secondary, upper secondary, tertiary attainments, and for the continuous specification, extending results shown in table 3 to all quantiles of the distribution. From these figures it comes out clearly that the fall in EWP concerns all the quantiles of the wage distribution, and that the fall in EWP is stronger at the bottom of the wage distribution, especially for the tertiary dummy and for the continuous specification. Further, the OLS estimates confirms the results of the quantile regressions: EWP decreased only after 1995, and more markedly after 2000, using both continuous and categorical specifications for education.

As mentioned above, we also make use of a finer classification for education, in which it is possible to distinguish two categories (general and vocational) for upper secondary education and three categories (humanistic, professional, and scientific) for tertiary degrees. From Table 4 it can be observed that EWP decrease significantly for both categories of upper secondary school ('general' and 'vocational'), confirming previous results. As for different categories of graduates, the premia generally decrease at all quantiles of the wage distribution, even though the statistical significance of these variations differs according to the type of degree considered. More specifically, the premia for humanistic degrees decrease significantly at all quantiles, except for the $75^{\text {th }}$, from $29.9 \%$ to $47.6 \%$, as well as wage premia for professionals that decrease over the entire distribution (from $-24 \%$ to $-43 \%$ in different quantiles). As for scientific degrees, EWP decrease over time but not in a significant way. Finally, the bottom panel of table 4 shows the OLS estimates. Interestingly, they are negative and significant for all the categories, also for the scientific degrees whose variations over time were not significant using quantile regressions.

Using this finer classification, then, suggests that composition effects do not play a significant role, since sub-groups identified within the upper secondary

23 The estimated coefficients of the educational dummies have to be interpreted as differentials with respect to the omitted category, i.e. having a primary school degree (which includes also those who have not achieved any educational degree). Note that the related share of the omitted dummy decreased over time, since educational levels are increasing in Italy. This means that belonging to this category should be increasingly related to unskilled and low paid occupations in the labour market. Ceteris paribus, the premia of having lower secondary, upper secondary and tertiary degrees could have increased over time, since the labour market should have rewarded the omitted category ever less. This is not the case: lower secondary, upper secondary and tertiary degrees reduce their EWP with respect to the omitted category. 
and tertiary attainments display similar trends with respect to their aggregate classification. For this reason, in the following of the analysis we consider the classification in four dummies. Figure 2. $a-f$ extends to all quantiles of the wage distribution the variations over time of the different types of upper secondary and tertiary attainments. From figure $2 f$ it is also possible to note that the variations over time for scientific degrees are always negative and very close to be statistically different from zero, as in the OLS estimates.

\subsection{EWP dynamics in the public sector: a different pattern}

We perform the same exercise developed in section 5.1 for the sample of public sector employees. As in table 3, the first column of table 5 gives the EWP at selected quantiles for the year 1993 for the public sector, while the other columns show the variations between the coefficient for that given year (1995, $1998,2000,2002,2004)$ and the 1993 coefficient. In the last column of table 5 we also set out the percentage variations occurring from 1993 to 2004. The first clear finding that emerges from table 5 is that over time variations in EWP between 1993 and the subsequent years (from 1995 to 2004) are hardly ever significant, for all educational attainments. In particular, using the classification in dummies the variations prove never to be significant, for all the years. When using the continuous classification some variations are significant: for instance EWP increase between 1993 and 2004 at the 10th and the 90th percentile, by $33.3 \%$ and $32.4 \%$ respectively. Similar results are derived with OLS estimates: variations over time related to the dummy specification are not significant, while EWP increase using a continuous specification, by $30 \%$.

As far as the differences between the private and private sector in a cross sectional dimension are concerned, comparing table 3 and table 5, we observe that lower secondary and upper secondary wage premia are generally lower in the public sector than in the private sector and that their time variations are not statistically significant, in contrast with the falling dynamics found in the private sector. With regard to graduate workers, in a cross section perspective in 1993, the premia in the public sector are notably lower than in the private sector across the wage distribution.

The stability of the EWP in the public sector might be related to peculiar institutional factors in this sector, such as stronger union power and the reforms in the wage setting system introduced in 1993 and 1998. Naticchioni and Ricci (2008) show that these reforms may have played a role in accounting for the dynamics in EWP and inequality trends. 


\section{Robustness checks}

The choices concerning the econometric specification of the wage equation or the sub-sample of workers considered might have affected previous results regarding the decrease of EWP from 1993 to 2004 in the private sector. In order to take these potential arguments into account we carried out some robustness checks. ${ }^{24}$

In the first robustness check we restrict our analysis to full time male workers aged 15-64, in order to test whether the increases both in the participation decisions and in the EWP of women over time could have affected the estimates performed on the whole sample. As shown in column (1) of Table 6, however, the results do not change much: the EWP decrease over time and these variations are mostly significant for upper secondary and tertiary education, except for graduates situated at the $90^{\text {th }}$ percentile. This result, together with the OLS estimates, suggests that the cross sectional EWP for females show no remarkable distinctive features with respect to those of the male sample.

Another robustness check regards the inclusion of self-employed in our sample. Actually one might argue that wage compression in Italy could have induced highly educated employees to move towards self-employment, especially in the case where these incentives had been increasing over time. If this were the case, the evolution of educational premia would have been affected by non-random transitions across groups and by selection biases. Column (2) of table 6, again, shows that this is not the case, using both quantile and OLS estimates: EWP decline between 1993 and 2004, especially in the lower part of the distribution. ${ }^{25}$

A further robustness check concerns a more general specification of the wage equation (2). We depart from a standard Mincerian specification including additional covariates available in the SHIW database, which might be related to our human capital variables. In particular, in this specification we add as regressors age (8 dummies), occupation (5 dummies), region (5 dummies),

24 The strategy of carrying out several robustness checks for different sub-groups and different specifications allows us to control to some extent for the endogeneity of schooling, as credible instrumental variables or randomized experiment are not available for an analysis over time. As already stressed, previous papers on returns to education in Italy derived convincing instrumental variables in the SHIW data, exploiting information concerning the schooling reforms in the late 60s (Brunello et al. 2001). However, these instrumental variables become much less convincing when the focus of the analysis is the time dynamic of EWP. Actually, since the effects of schooling reforms change according to the population sub-group involved in the reforms, the group of compliers affected by the instruments changes over time, affecting in turn the dynamic comparison of the estimates. See Angrist et al. (1996).

${ }^{25}$ Note that when we include self-employed we have to consider yearly labour income instead of monthly labour income, for both employees and self-employed. For this reason, the coefficients of this column cannot be compared to the ones of the other columns. 
industry (9 dummies), firm size, hours worked, par-time/fulltime. ${ }^{26}$ As shown in the third column of table 6, the EWP are lower both in 1993 and 2004, confirming that some of the additional variables actually capture part of the educational premia. For what concerns the time variation, EWP of tertiary education decrease significantly at all quantiles of the distribution (except for the $75^{\text {th }}$ percentile), as well as the premia associated to upper secondary degrees, while the EWP for lower secondary did not vary significantly over time (except for the $90^{\text {th }}$ percentile). The OLS estimates confirm this evidence. ${ }^{27}$

In the last robustness check we investigate whether the decline in EWP changes when separate regressions are performed for the young and adults employed in private sector (under and over 35), i.e. whether some discontinuities in age are at work. Actually, in the nineties several reforms concerning the education system were carried out in Italy. The school system was reformed between 1993 and 2004 (in 2000 and 2003), as well as the tertiary education system (in 1999). A possible explanation for the falling EWP might then be related to a negative impact of such reforms on the average quality of colleges and graduates: firms attribute lower premia to formal education since its quality decreases over time. If this were the case, we would expect stable patterns for individuals over 35 (not affected by the reforms) and declining premia for the young, who are also the more educated segment of the workforce. Evidence from table 7 does not support such an explanation: the negative variations of premia for upper secondary and tertiary education are mostly significant for individuals over 35, while they are usually not significant for those under 35, both using OLS and quantile regressions.

\section{Conclusion}

The main purpose of this paper is to analyse the dynamics of EWP between 1993 and 2004 across the wage distribution. We find out that in the private sector wage premia of lower secondary and upper secondary education decline considerably over time at all quantiles. Interestingly enough, also the premia associated with tertiary education decline significantly over time. Similar results

\footnotetext{
${ }^{26}$ In table A1 in appendix we report the descriptive statistics for all these addictional variables, except for regional dummies (the sample design of the SHIW data guarantees that they are quite stable over time).

27 Others robustness checks have been carried out by the authors, and are available on request. First, we used as dependent variable the hourly wages instead of monthly wages, in order to control for different working time across individuals and to avoid the correction for part timers used to compute the monthly wages. Results do not change much, consistently also with the figures showed in column (3) of table 6, in which the working time has been included as covariate. Second, we used a quadratic specification for experience, instead of the categorical specification. Also in this case results do not change. We prefer to rely on the categorical specification, as in other related papers (Autor et al., 2005) in order to control for possible strong non-linear trends.
} 
hold when a finer classification concerning the type of high-school and tertiary attainments is used, and even after controlling for a wide range of robustness checks to tackle sample selection issues. As for public sector employees, on the other hand, the time variations of wage premia are hardly ever statistically different from zero across the wage distribution. The different patterns of EWP between private and public sectors are probably due to distinctive institutional features of the two labour markets, and to different labour market reforms introduced in the two sectors.

Further, our findings call into question the empirical evidence available for most of developed countries, and especially for the Anglo-Saxon ones, which have experienced increasing returns to education and increasing earnings inequality. Indeed, we provide additional evidence in favour of the thesis that all the phenomena related to increasing EWP and inequality are much less pronounced in continental Europe. And even within the European evidence, where EWP are usually stable or slightly increasing, the Italian case seems to be quite peculiar, because EWP fall over time. In this paper we do not investigate which are the driving forces behind the falling EWP in Italy. It could be related to the technological contents of productive process, or it could be linked to other explanations, such as the evolution over time of supply and demand of education, the 'organizational change', the impact of international trade on domestic labour market, or to institutional features differing between the US and Europe, and between continental European countries and Italy. ${ }^{28}$ Future research will further investigate the relation between the falling in EWP and inequality in both the private and public sector, disentangling the impact of prices, covariates and unobserved factors (Naticchioni and Ricci, 2008).

\section{Acknowledgments}

We wish to thank Andrea Brandolini, Piero Cipollone, Bart Cockx, Muriel Dejemeppe, Claudio Lucifora, Andrea Neri, Paolo Piacentini, Franco Peracchi, Daniela Vuri, Henri Sneessens, Bruno Van der Linden and Robert Waldmann, as well as seminar participants in the Brucchi Luchino 2006 conference, the AIEL 2006 conference, the DSE-ISFOL workshop, and the meeting of the IEIILM research group.

${ }^{28}$ See for instance Acemoglu (2002) for a detailed survey of all this literature. 


\section{References}

Acemoglu, D. (2002) Technical Change, Inequality, and the Labor Market, Journal of Economic Literature, 40, pp.7-72.

Angrist, J.D., G.W. Imbens, D.B. Rubin (1996), Identification of Causal Effects Using Instrumental Variables, Journal of the American Statistical Association, 91, 444472.

Arias, O., Hallock, K.F., Sosa-Escudero, W. (2001) Individual Hererogeneity in the returns to schooling: instrumental variable quantile regression using twins data, Empirical Economics, 26, pp.7-40.

Ashenfelter, O., C. Harmon and H. Oosterbeek (1999) A Review of Estimates of the Schooling/Earnings Relationship with Test for Publication Bias, Labour Economics, n. 6, pp. 453-470

Autor, D.A, Katz, L.F., Kearney, M.S. (2005) Rising Wage Inequality: The Role of Composition and Prices, NBER no. 11628.

Bound, J. , G. Johnson (1992) Changes in the Structure of Wages in the 1980s: An Evaluation of Alternative Explanations, American Economic Review, 82, pp.371-92.

Brandolini, A., Cipollone, P. (2002) Return to education in Italy: 1992-1997, mimeo available at the web page http://www.econpol.unisi.it/monnet/paper_set04/brandolini_cipollone.pdf.

Brunello G., Comi S. and Lucifora C. (2001) The Returns to Education in Italy: A New Look at the Evidence, in Harmon C., Walker I. and Westergard-Nielsen N. (eds), The Returns to Education in Europe, Cheltenham (UK) Edward Elgar.

Brunello G., Miniaci R. (1999) The Economics Returns to Schooling for Italian Men. An Evaluation Based on Instrumental Variables, Labour Economics, vol. 6, n. 4, pp.509-519.

Buchinsky, M. (1994) Changes in the U.S. Wage Structure 1963-1987: Application of Quantile Regression, Econometrica 62, pp.405-458.

Card, D. (2001) Estimating the Return to Schooling: Progress on Some Persistent Econometric Problems, Econometrica, vol. 69(5), pp. 1127-60.

Cunha, F., Heckman, J. (2007) The Technology of Skill Formation, American Economic Review, American Economic Association, vol. 97(2), pages 31-47, May.

Dell'Aringa, C., Lucifora, C., Origo, F. (2007) Public Sector Pay and Regional Competitiveness: A First Look at Regional Public-Private Wage Differentials in Italy, Manchester School, Vol. 75, Issue 4, pp. 445-478.

Fersterer J. F. R. Winter-Ebmer (2003) Are Austrian Returns to Education falling over time?, Labour Economis, vol. 10(1), pp. 73-89.

Fitzenberger, B, Kurz, C. (2003) New insights on Earnings Trends across Skill Groups and Industries in West Germany, 2003, Empirical Economics, Vol. 28, pp. 479-514.

Giustinelli, P. (2004) Quantile Regression Evidence on Italian Education Returns", Rivista di Politica Economica, XI-XII.

Gottschalk, P., T.M. Smeeding (1997) Cross-National Comparisons of Earnings and Income Inequality, Journal of Economic Literature, 35, 633-687.

Gregory, R.G., Borland, J. (1999) Recent developments in public sector labor market, in Ashenfelter, O., Card, D. (eds), Handbook of Labor Economics, Vol.3. 
Hartog, J., Pereira, P., Vieira, J. (2001) Changing returns to education in Portugal during the 1980s and early 1990s: OLS and quantile regression estimators, Applied Economics, 33:1021-1037.

Heckman, J. J., Stixrud, J., Urzua, S. (2006) The Effects of Cognitive and Noncognitive Abilities on Labor Market Outcomes and Social Behavior, Journal of Labor Economics, vol. 24(3), pages 411-482, July.

Hornstein, A., Krusell, P., Violante, G. (2005) The Effects of Technical Change on Labor Market Inequalities" in The Handbook of Economic Growth (P. Aghion, and S. Durlauf, Eds.), Amsterdam, The Netherlands: Elsevier, 2005.

Juhn, C., Murphy, K.M, Pierce, B. (1993) Wage Inequality and the Rise in Returns to Skill, Journal of Political Economy, 101, pp.410-42.

Koenker, R., Basset, G. (1978) Regression Quantiles, Econometrica, vol. 46, pp. 3350.

Koenker, R., Basset, G. (1982) Robust test for Heteroscedasticity Based on Regression Quintiles, Econometrica, 50, pp.43-61.

Lilla, M. (2005) Disuguaglianze salariali in Italia: nuove evidenze dai microdati SHIW, Politica economica, no.1, pp. 71-102.

Machado, J., J. Mata (2001) Earning functions in Portugal 1982-1994: Evidence from quantile regression, Empirical Economics, vol. 26(1), pp. 115-134.

Magoula, T.; Psacharopoulos, G. (1999) Schooling and monetary rewards in Greece: an over-education false alarm?, Applied Economics, Vol.31 (12), pp 1589-1597.

Martins, P., Pereira, P. (2004) Does Education Reduce Wage Inequality? Quantile Regression Evidence From 16 Countries, Labour Economics, 11(3), 355-371.

Mincer J. (1974) Schooling, Experience and Earnings, Columbia University Press, New York.

Peracchi, F. (2006) Educational wage premia and the distribution of earnings: an international perspectives, in E.Hanushek and F.Welch (eds.), Handbook of the Economics of Education, North-Holland, Amsterdam.

Naticchioni, P., Ricci, A. (2008) A reassessment of wage inequality in Italy, forthcoming as DSE-ISFOL working paper.

OECD (2005) Education at a glance, Paris.

OECD (2006) Education at a glance, Paris.

Palme, M.O, Wright, R.E. (1998) Changes in the rate of return to education in Sweden: 1968-199, Applied Economics, Volume 30 (12), pp.1653 - 1663. 
Tables and Figures

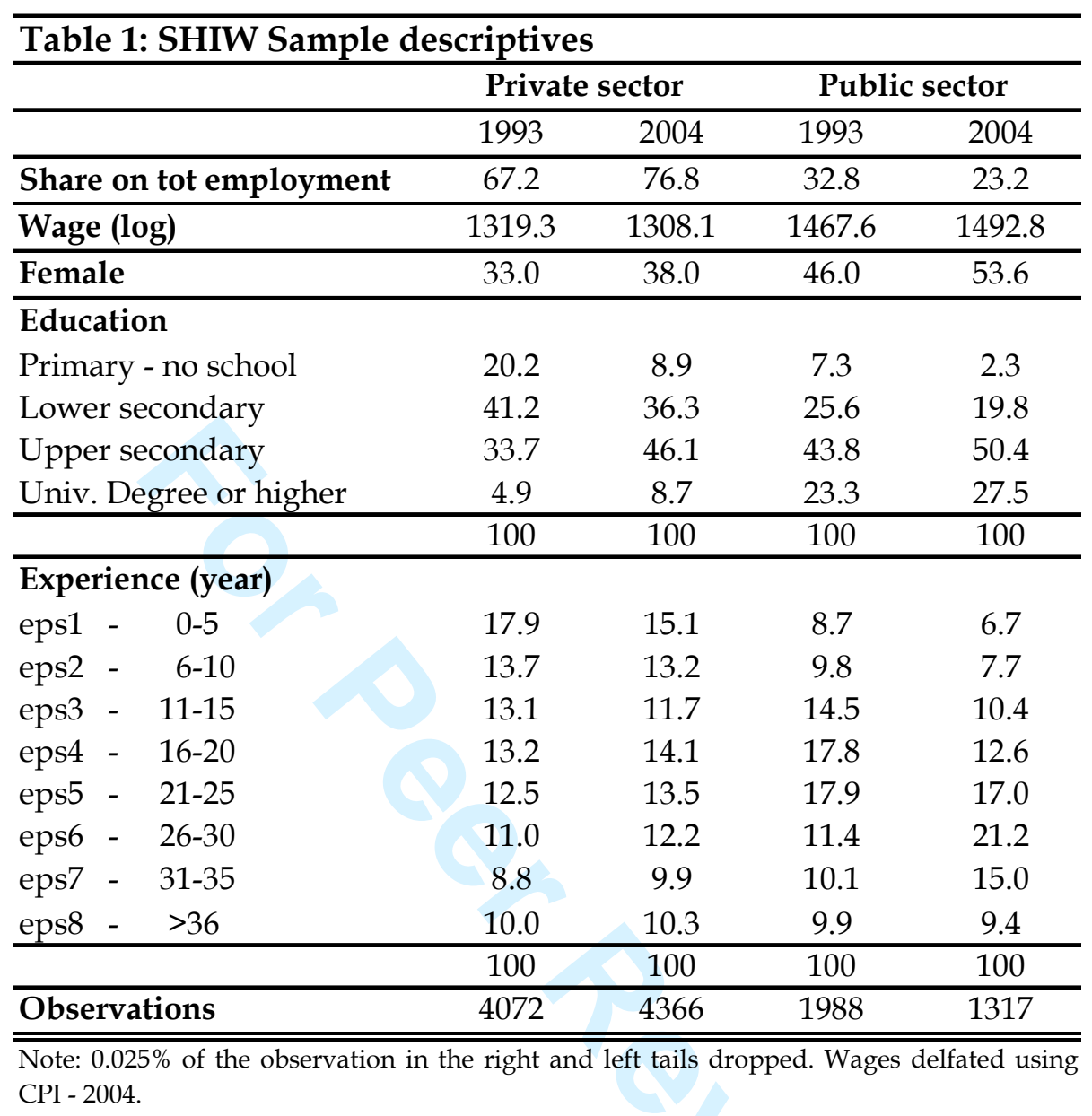

Table 2: Sample descriptives with a finer classification for education

\begin{tabular}{lcccc}
\hline & \multicolumn{2}{c}{ Private sector } & \multicolumn{2}{c}{ Public sector } \\
\hline & 1995 & 2004 & 1995 & 2004 \\
\hline Upper secondary & & & & \\
\hline General (liceo) & 8.4 & 12.1 & 12.4 & 14.1 \\
Vocational & 91.6 & 87.9 & 87.6 & 85.9 \\
\hline & 100 & 100 & 100 & 100 \\
\cline { 2 - 5 } Observations & 1474 & 2002 & 1049 & 662 \\
\hline Tertiary education & & & & \\
\hline Humanistic & 17.0 & 29.2 & 46.1 & 44.1 \\
Professionals & 37.9 & 29.2 & 18.4 & 16.0 \\
Scientific & 45.1 & 41.7 & 35.5 & 39.9 \\
\hline Observations & 100 & 100 & 100 & 100 \\
\hline \hline Note: $0.05 \%$ of the observation in the right and left tails dropped. &
\end{tabular}


Table 3: Quantile Estimates of Educational Wage Premia for employees in the private sector, using continuous and (4) dummies specification for education

\begin{tabular}{|c|c|c|c|c|c|c|c|c|}
\hline & $\begin{array}{c}\text { Dep var } \\
\text { log monthly wage }\end{array}$ & 1993 & $\begin{array}{c}\text { var. } \\
93-95 \\
\end{array}$ & $\begin{array}{c}\text { var. } \\
93-98\end{array}$ & $\begin{array}{c}\text { var. } \\
93-00\end{array}$ & $\begin{array}{c}\text { var. } \\
93-02 \\
\end{array}$ & $\begin{array}{c}\text { var. } \\
93-04\end{array}$ & $\begin{array}{l}\text { \%var. } \\
93-04 \\
\end{array}$ \\
\hline \multirow{4}{*}{ q10 } & Lower secondary & 0.149 & -0.003 * & 0.029 * & 0.029 * & -0.053 * & -0.028 * & -0.186 \\
\hline & Upper Secondary & 0.431 & -0.064 * & -0.070 * & $-0.070 *$ & -0.140 & -0.173 & -0.401 \\
\hline & University & 0.730 & -0.066 * & * -0.113 * & -0.113 * & -0.214 & -0.260 & -0.356 \\
\hline & Continuous & 0.056 & -0.007 * & -0.016 & -0.016 & -0.017 & -0.023 & -0.408 \\
\hline \multirow{4}{*}{$\mathrm{q} 25$} & Lower secondary & 0.122 & 0.013 * & 0.029 * & 0.029 * & -0.011 * & -0.042 * & -0.346 \\
\hline & Upper Secondary & 0.372 & -0.020 * & -0.059 & -0.059 & -0.121 & -0.137 & -0.368 \\
\hline & University & 0.689 & -0.014 * & -0.133 & -0.133 & -0.188 & -0.202 & -0.293 \\
\hline & Continuous & 0.049 & -0.002 * & -0.010 & -0.010 & -0.015 & -0.015 & -0.302 \\
\hline \multirow{4}{*}{ q50 } & Lower secondary & 0.139 & 0.009 * & 0.016 * & $0.016^{*}$ & -0.024 * & -0.071 & -0.509 \\
\hline & Upper Secondary & 0.387 & -0.008 * & -0.066 & -0.066 & -0.122 & -0.143 & -0.368 \\
\hline & University & 0.759 & 0.016 * & -0.162 & -0.162 & -0.184 & -0.195 & -0.257 \\
\hline & Continuous & 0.050 & 0.000 * & -0.010 & -0.010 & -0.013 & -0.012 & -0.237 \\
\hline \multirow{4}{*}{ q75 } & Lower secondary & 0.153 & 0.018 * & -0.009 * & -0.009 * & -0.070 & -0.088 & -0.574 \\
\hline & Upper Secondary & 0.445 & -0.021 * & -0.075 & -0.075 & -0.160 & -0.171 & -0.384 \\
\hline & University & 0.803 & 0.085 * & -0.055 * & -0.055 * & -0.111 & -0.139 & -0.173 \\
\hline & Continuous & 0.057 & $-0.001^{*}$ & -0.008 & -0.008 & -0.009 & -0.012 & -0.205 \\
\hline \multirow{4}{*}{ q90 } & Lower secondary & 0.154 & 0.022 * & $0.005^{*}$ & 0.005 * & -0.046 * & -0.094 & -0.610 \\
\hline & Upper Secondary & 0.487 & 0.007 * & -0.044 * & -0.044 & -0.104 & -0.144 & -0.295 \\
\hline & University & 0.872 & 0.034 * & 0.013 * & 0.013 * & -0.030 & -0.150 & -0.172 \\
\hline & Continuous & 0.065 & -0.003 * & -0.005 * & -0.005 * & $-0.006^{*}$ & -0.009 & -0.131 \\
\hline \multirow{4}{*}{ OLS } & Lower secondary & 0.145 & $0.020^{*}$ & 0.013 * & 0.013 * & -0.053 & -0.070 & -0.479 \\
\hline & Upper Secondary & 0.431 & -0.016 * & -0.068 & -0.068 & -0.144 & -0.170 & -0.394 \\
\hline & University & 0.775 & 0.020 * & -0.110 & -0.110 & -0.160 & -0.204 & -0.264 \\
\hline & Continuous & 0.057 & $-0.003^{*}$ & -0.009 & -0.009 & -0.013 & -0.015 & -0.258 \\
\hline
\end{tabular}

Omitted dummy: no-school - primary. In the column 1993 are reported the coefficients for that year, while in the columns from 1995 to 2004 we report the difference between the coefficient at that given year and the coefficient in 1993 . Coefficients in all years are significant at $5 \%$, except those in italics. * stands for variation over time (with respect to 1993) not statistically different at $5 \%$ 


\begin{tabular}{|c|c|c|c|c|c|}
\hline \multicolumn{6}{|c|}{$\begin{array}{l}\text { Table 4: Quantile Estimates of Educational Wage Premia for employees in the } \\
\text { private sector, using a } 7 \text { dummies specification for education }\end{array}$} \\
\hline & $\begin{array}{c}\text { Dep. Var. } \\
\log \text { monthly wage }\end{array}$ & 1995 & 2004 & Variation & $\%$ Var. \\
\hline \multirow{6}{*}{ q10 } & Lower secondary & 0.161 & 0.093 & -0.068 & $-42.2 *$ \\
\hline & Upper Secondary: no liceo & 0.356 & 0.243 & -0.114 & -31.9 \\
\hline & Upper Secondary: liceo & 0.519 & 0.269 & -0.250 & -48.1 \\
\hline & Graduate: Humanistic & 0.786 & 0.411 & -0.374 & -47.6 \\
\hline & Graduate: Professionals & 0.820 & 0.464 & -0.356 & -43.4 \\
\hline & Graduate: Scientific & 0.713 & 0.588 & -0.125 & $-17.6 *$ \\
\hline \multirow{6}{*}{ q25 } & Lower secondary & 0.143 & 0.078 & -0.064 & $\begin{array}{ll}-45.1 \\
\end{array}$ \\
\hline & Upper Secondary: no liceo & 0.344 & 0.232 & -0.112 & -32.6 \\
\hline & Upper Secondary: liceo & 0.471 & 0.320 & -0.152 & -32.2 \\
\hline & Graduate: Humanistic & 0.660 & 0.383 & -0.277 & -41.9 \\
\hline & Graduate: Professionals & 0.740 & 0.475 & -0.265 & -35.8 \\
\hline & Graduate: Scientific & 0.746 & 0.638 & -0.108 & $-14.5 *$ \\
\hline \multirow{6}{*}{ q50 } & Lower secondary & 0.146 & 0.071 & -0.075 & -51.2 \\
\hline & Upper Secondary: no liceo & 0.366 & 0.244 & -0.123 & -33.5 \\
\hline & Upper Secondary: liceo & 0.468 & 0.284 & -0.184 & -39.3 \\
\hline & Graduate: Humanistic & 0.618 & 0.433 & -0.185 & -29.9 \\
\hline & Graduate: Professionals & 0.831 & 0.574 & -0.257 & -31.0 \\
\hline & Graduate: Scientific & 0.772 & 0.661 & -0.111 & -14.4 * \\
\hline \multirow{6}{*}{ q75 } & Lower secondary & 0.173 & 0.066 & -0.107 & -61.7 \\
\hline & Upper Secondary: no liceo & 0.427 & 0.264 & -0.163 & -38.3 \\
\hline & Upper Secondary: liceo & 0.559 & 0.311 & -0.248 & -44.4 \\
\hline & Graduate: Humanistic & 0.694 & 0.453 & -0.241 & $-34.8 *$ \\
\hline & Graduate: Professionals & 0.937 & 0.711 & -0.226 & -24.1 \\
\hline & Graduate: Scientific & 0.921 & 0.789 & -0.132 & -14.3 * \\
\hline \multirow{6}{*}{ q90 } & Lower secondary & 0.166 & 0.077 & -0.089 & -53.8 \\
\hline & Upper Secondary: no liceo & 0.478 & 0.336 & -0.142 & -29.8 \\
\hline & Upper Secondary: liceo & 0.506 & 0.438 & -0.068 & -13.5 * \\
\hline & Graduate: Humanistic & 0.882 & 0.514 & -0.369 & -41.8 \\
\hline & Graduate: Professionals & 1.089 & 0.674 & -0.415 & -38.1 \\
\hline & Graduate: Scientific & 0.896 & 0.866 & -0.031 & -3.4 * \\
\hline \multirow{6}{*}{ OLS } & Lower secondary & 0.165 & 0.077 & -0.088 & -53.5 \\
\hline & Upper Secondary: no liceo & 0.405 & 0.254 & -0.151 & -37.3 \\
\hline & Upper Secondary: liceo & 0.520 & 0.317 & -0.203 & -39.0 \\
\hline & Graduate: Humanistic & 0.628 & 0.449 & -0.179 & -28.5 \\
\hline & Graduate: Professionals & 0.872 & 0.569 & -0.303 & -34.8 \\
\hline & Graduate: Scientific & 0.814 & 0.698 & -0.117 & -14.3 \\
\hline
\end{tabular}

Omitted dummy: no-school - primary. All coefficients in 1995 and 2004 are significant at $5 \%$. ${ }^{*}$ stands for variation over time not statistically different at $5 \%$ 
Table 5: Quantile Estimates of Educational Wage Premia for employees in the public sector, using continuous and (4) dummies specification for education

\begin{tabular}{|c|c|c|c|c|c|c|c|c|}
\hline & $\begin{array}{c}\text { Dep var } \\
\text { g monthly wage }\end{array}$ & 1993 & $\begin{array}{c}\text { var. } \\
93-95 \\
\end{array}$ & $\begin{array}{c}\text { var. } \\
93-98 \\
\end{array}$ & $\begin{array}{c}\text { var. } \\
93-00 \\
\end{array}$ & $\begin{array}{c}\text { var. } \\
93-02 \\
\end{array}$ & $\begin{array}{c}\text { var. } \\
93-04 \\
\end{array}$ & $\begin{array}{l}\text { \%var. } \\
93-04 \\
\end{array}$ \\
\hline \multirow{4}{*}{ q10 } & Lower secondary & 140 & -0.016 * & $0.007 *$ & -0.058 * & 0.194 * & $0.004^{*}$ & 0.031 \\
\hline & Upper & 266 & $-0.040 *$ & $-0.044 *$ & $-0.017^{*}$ & 0.212 * & 0.053 * & 0.198 \\
\hline & Univ & 0.394 & -0.069 * & $-0.044^{*}$ & -0.019 * & 0.258 * & 0.081 * & 0.206 \\
\hline & Continuous & 0.028 & -0.005 * & -0.002 * & 0.004 * & 0.010 & 0.009 & 0.333 \\
\hline \multirow{4}{*}{ q25 } & Lower secon & 0.126 & $-0.007^{*}$ & $0.008^{*}$ & $0.005^{*}$ & $0.056^{*}$ & $0.004^{*}$ & 0.034 \\
\hline & Uppe & & -0.015 * & -0.030 * & 0.018 * & 0.054 * & -0.002 * & -0.008 \\
\hline & Uni & 0.368 & $8 *$ & -0.067 * & 0.017 * & 0.076 * & 0.042 * & 0.114 \\
\hline & Contir & 0.028 & $-0.004^{*}$ & -0.008 & $0.000^{*}$ & $0.004^{*}$ & $0.005^{*}$ & 0.175 \\
\hline \multirow{4}{*}{ q50 } & Lower & - & $0.023^{*}$ & $0.054^{*}$ & $-0.004^{*}$ & $0.067^{*}$ & -0.043 * & -0.339 \\
\hline & Uppe & 25 & -0.022 * & -0.002 * & -0.022 * & 0.065 * & -0.043 * & -0.171 \\
\hline & $\mathrm{U}$ & 0.3 & $-0.035 *$ & -0.016 * & $-0.005 *$ & 0.097 * & 0.033 * & 0.092 \\
\hline & Cont & 0.028 & $-0.005^{*}$ & $\begin{array}{l}-0.007 \\
\end{array}$ & 0.000 * & $0.004^{*}$ & 0.005 * & 0.167 \\
\hline \multirow{4}{*}{ q75 } & Low & 01 & $0.039^{*}$ & $0.038^{*}$ & $0.020^{*}$ & -0.002 * & 0.008 * & 0.065 \\
\hline & Upp & 0.256 & 1 * & $-0.018 *$ & -0.003 * & 0.010 * & -0.003 * & -0.012 \\
\hline & & & 0.008 * & -0.036 * & 0.030 * & 0.073 * & $5 *$ & 0.299 \\
\hline & Continuous & 0.032 & $-0.003^{*}$ & $-0.004^{*}$ & $0.002^{*}$ & $0.007^{*}$ & $0.010^{*}$ & 0.297 \\
\hline \multirow{4}{*}{ q90 } & Lower secondar & 0.128 & $0.053^{*}$ & $0.004^{*}$ & -0.012 * & $-0.015^{*}$ & $0.059^{*}$ & 0.464 \\
\hline & Upper & 0.299 & 0.018 * & -0.070 * & -0.056 * & -0.004 * & 0.018 * & 0.062 \\
\hline & University & & -0.028 * & -0.039 * & 0.062 * & 0.068 * & 0.181 * & 0.321 \\
\hline & Continuous & 0.043 & -0.003 * & -0.004 * & 0.008 * & 0.010 * & 0.014 & 0.324 \\
\hline \multirow{4}{*}{ OLS } & Lower secondar & 0.134 & $0.017^{*}$ & $0.031^{*}$ & -0.025 * & $0.044^{*}$ & -0.016 * & -0.117 \\
\hline & Upper & 0.26 & -0.013 * & -0.016 * & -0.017 * & 0.043 * & -0.024 * & -0.090 \\
\hline & & & -0.034 * & -0.010 * & $0.017^{*}$ & $0.104^{*}$ & 0.081 * & 0.194 \\
\hline & Continuous & 0.032 & -0.004 & -0.003 & $0.004^{3}$ & 0.007 & 0.010 & 0.306 \\
\hline
\end{tabular}

Omitted dummy: no-school - primary. In the column 1993 are reported the coefficients for that year, while in the columns from 1995 to 2004 we report the difference between the coefficient at that given year and the coefficient in 1993. Coefficients in all years are significant at $5 \%$, except those in italics. * stands for variation over time (with respect to 1993) not statistically different at $5 \%$ 
Table 6: Robustness checks of quantile Estimates of returns to education for employees in the private sector

\begin{tabular}{|c|c|c|c|c|c|c|c|c|}
\hline & & \multicolumn{2}{|c|}{$\begin{array}{l}\text { (1) Only male } \\
\text { fulltime }\end{array}$} & \multicolumn{3}{|c|}{$\begin{array}{l}\text { (2) spec. with } \\
\text { self-employed }\end{array}$} & \multicolumn{2}{|c|}{$\begin{array}{c}\text { (3) Full } \\
\text { specification }\end{array}$} \\
\hline & & 1993 & $\begin{array}{l}\text { var. } \\
(04-93)\end{array}$ & 1993 & $\begin{array}{c}\text { var. } \\
(04-93)\end{array}$ & & 1993 & $\begin{array}{l}\text { var. } \\
(04-93)\end{array}$ \\
\hline \multirow{4}{*}{ q10 } & Lower secondary & 0.114 & -0.034 * & 0.434 & -0.173 & * & 0.042 & $-0.044 \times$ \\
\hline & Upper Secondary & 0.389 & -0.165 & 0.762 & -0.315 & & 0.116 & -0.103 \\
\hline & University & 0.635 & $-0.137 *$ & 0.968 & -0.252 & & 0.266 & -0.170 \\
\hline & Continuous & 0.048 & -0.016 & 0.075 & -0.023 & & 0.019 & -0.016 \\
\hline \multirow{4}{*}{ q25 } & Lower secondary & 0.114 & -0.065 & 0.343 & -0.160 & & 0.062 & $-0.032 *$ \\
\hline & Upper Secondary & 0.376 & -0.163 & 0.640 & -0.271 & & 0.141 & -0.073 \\
\hline & University & 0.729 & -0.225 & 0.940 & -0.285 & & 0.294 & -0.140 \\
\hline & Continuous & 0.049 & -0.016 & 0.070 & -0.025 & & 0.019 & -0.010 \\
\hline \multirow{4}{*}{ q50 } & Lower secondary & 0.156 & -0.100 & 0.199 & -0.065 & & 0.057 & $-0.019 *$ \\
\hline & Upper Secondary & 0.408 & -0.165 & 0.484 & -0.152 & & 0.137 & -0.053 \\
\hline & University & 0.818 & -0.202 & 0.828 & -0.173 & & 0.298 & -0.111 \\
\hline & Continuous & 0.053 & -0.011 & 0.061 & -0.015 & & 0.019 & -0.008 \\
\hline \multirow{4}{*}{ q75 } & Lower secondary & 0.148 & -0.089 & 0.174 & -0.053 & * & 0.055 & $-0.036 *$ \\
\hline & Upper Secondary & 0.473 & -0.203 & 0.484 & -0.141 & & 0.117 & $-0.036 *$ \\
\hline & University & 0.885 & -0.155 & 0.817 & -0.047 & * & 0.278 & $-0.058 *$ \\
\hline & Continuous & 0.061 & -0.012 & 0.062 & -0.008 & & 0.017 & $-0.002 *$ \\
\hline \multirow{4}{*}{ q90 } & Lower secondary & 0.163 & -0.083 * & 0.212 & -0.154 & & 0.068 & -0.067 \\
\hline & Upper Secondary & 0.536 & -0.158 & 0.523 & -0.194 & & 0.163 & -0.103 \\
\hline & University & 0.988 & $-0.120 *$ & 0.962 & -0.156 & & 0.335 & -0.152 \\
\hline & Continuous & 0.070 & -0.009 & 0.069 & -0.005 & * & 0.024 & -0.011 \\
\hline \multirow{4}{*}{ OLS } & Lower secondary & 0.135 & -0.069 & 0.260 & -0.110 & & 0.058 & -0.034 * \\
\hline & Upper Secondary & 0.437 & -0.176 & 0.560 & -0.209 & & 0.143 & -0.082 \\
\hline & University & 0.800 & -0.145 & 0.873 & -0.184 & & 0.310 & -0.138 \\
\hline & Continuous & 0.059 & -0.013 & 0.067 & -0.017 & & 0.021 & -0.010 \\
\hline
\end{tabular}

Omitted dummy: no-school - primary. In the column 1993 are reported the coefficients for that year, while in the columns variat. (04-93) we report the difference between coefficients in 2004 and 1993 Coefficients in all years are significant at $5 \%$. * stands for variation over time (with respect to 1993 ) not statistically different at $5 \%$ 
Table 7: Educational wage premia for over and under 35

\begin{tabular}{|c|c|c|c|c|c|c|c|}
\hline & & \multicolumn{2}{|c|}{ (1) Over 35} & & \multicolumn{2}{|c|}{ (2) Under 35} & \\
\hline & & 1993 & 2004 & & 1993 & 2004 & \\
\hline \multirow{3}{*}{ q10 } & Lower secondary & 0.176 & 0.265 & * & 0.051 & 0.265 & \\
\hline & Upper Secondary & 0.438 & 0.236 & & 0.295 & 0.426 & * \\
\hline & University & 0.615 & 0.453 & & 0.672 & 0.625 & * \\
\hline \multirow{3}{*}{ q25 } & Lower secondary & 0.129 & 0.078 & & 0.124 & 0.220 & * \\
\hline & Upper Secondary & 0.367 & 0.244 & & 0.353 & 0.369 & * \\
\hline & University & 0.620 & 0.468 & & 0.718 & 0.591 & * \\
\hline \multirow{3}{*}{ q50 } & Lower secondary & 0.158 & 0.064 & & 0.098 & 0.120 & * \\
\hline & Upper Secondary & 0.409 & 0.259 & & 0.319 & 0.258 & * \\
\hline & University & 0.688 & 0.576 & * & 0.722 & 0.535 & \\
\hline \multirow{3}{*}{ q75 } & Lower secondary & 0.161 & 0.089 & & 0.095 & 0.001 & * \\
\hline & Upper Secondary & 0.494 & 0.318 & & 0.350 & 0.150 & \\
\hline & University & 0.824 & 0.731 & * & 0.668 & 0.396 & \\
\hline \multirow{3}{*}{ q90 } & Lower secondary & 0.201 & 0.092 & & 0.025 & 0.002 & * \\
\hline & Upper Secondary & 0.544 & 0.431 & & 0.309 & 0.154 & * \\
\hline & University & 0.924 & 0.793 & * & 0.624 & 0.472 & * \\
\hline \multirow{3}{*}{ OLS } & Lower secondary & 0.166 & 0.082 & & 0.092 & 0.114 & * \\
\hline & Upper Secondary & 0.454 & 0.282 & & 0.343 & 0.259 & * \\
\hline & University & 0.748 & 0.597 & & 0.695 & 0.518 & \\
\hline
\end{tabular}

Omitted dummy: no-school - primary. T stands for "test of the variation over time" and * stands for variation over time not statistically different at $5 \%$ 


\section{Figure 1: EWP variations at all quantiles, 1993-2004, using (4) dummies and continuous} specifications.
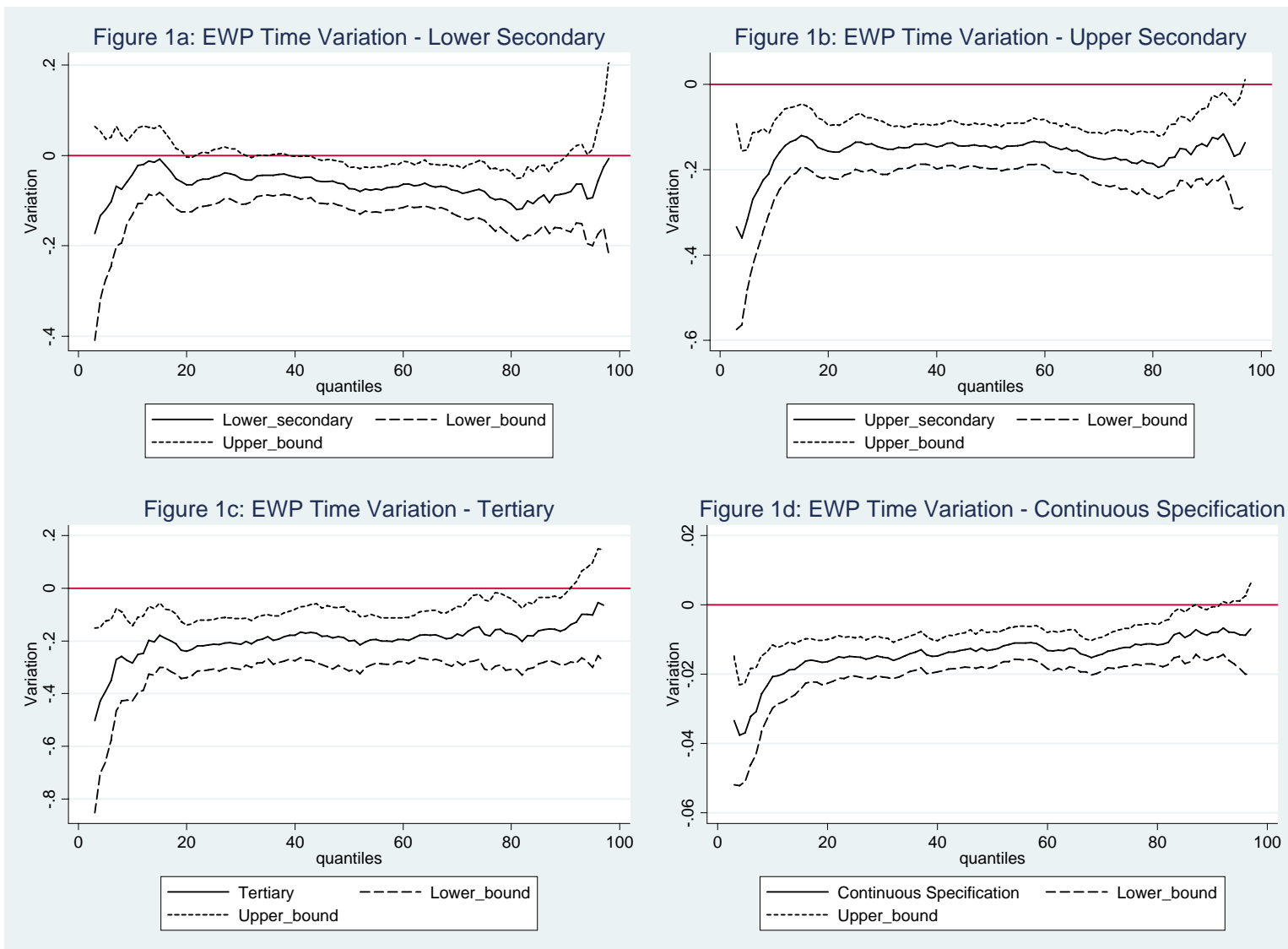


\section{Figure 2: EWP variations at all quantiles, 1993-2004, using (7) dummies and continuous specifications.}

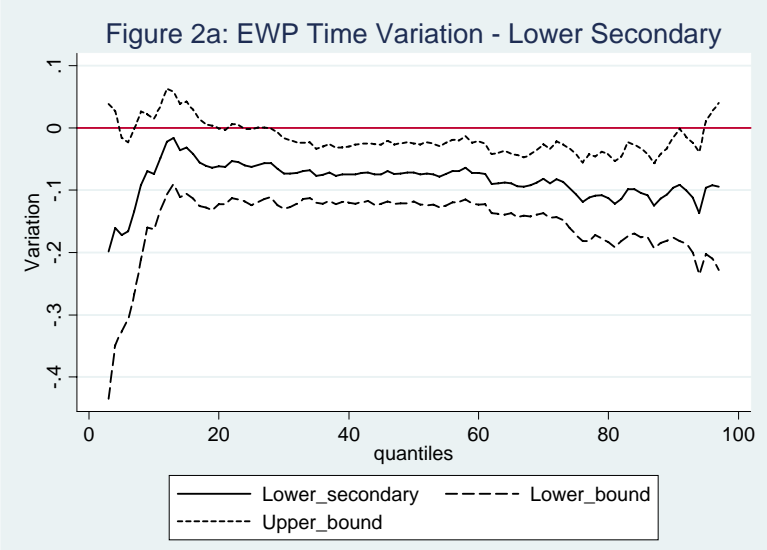

Figure 2b: EWP Time Variation - Vocational Upper Secondar

Figure 2c: EWP Time Variation - General Upper Secondary
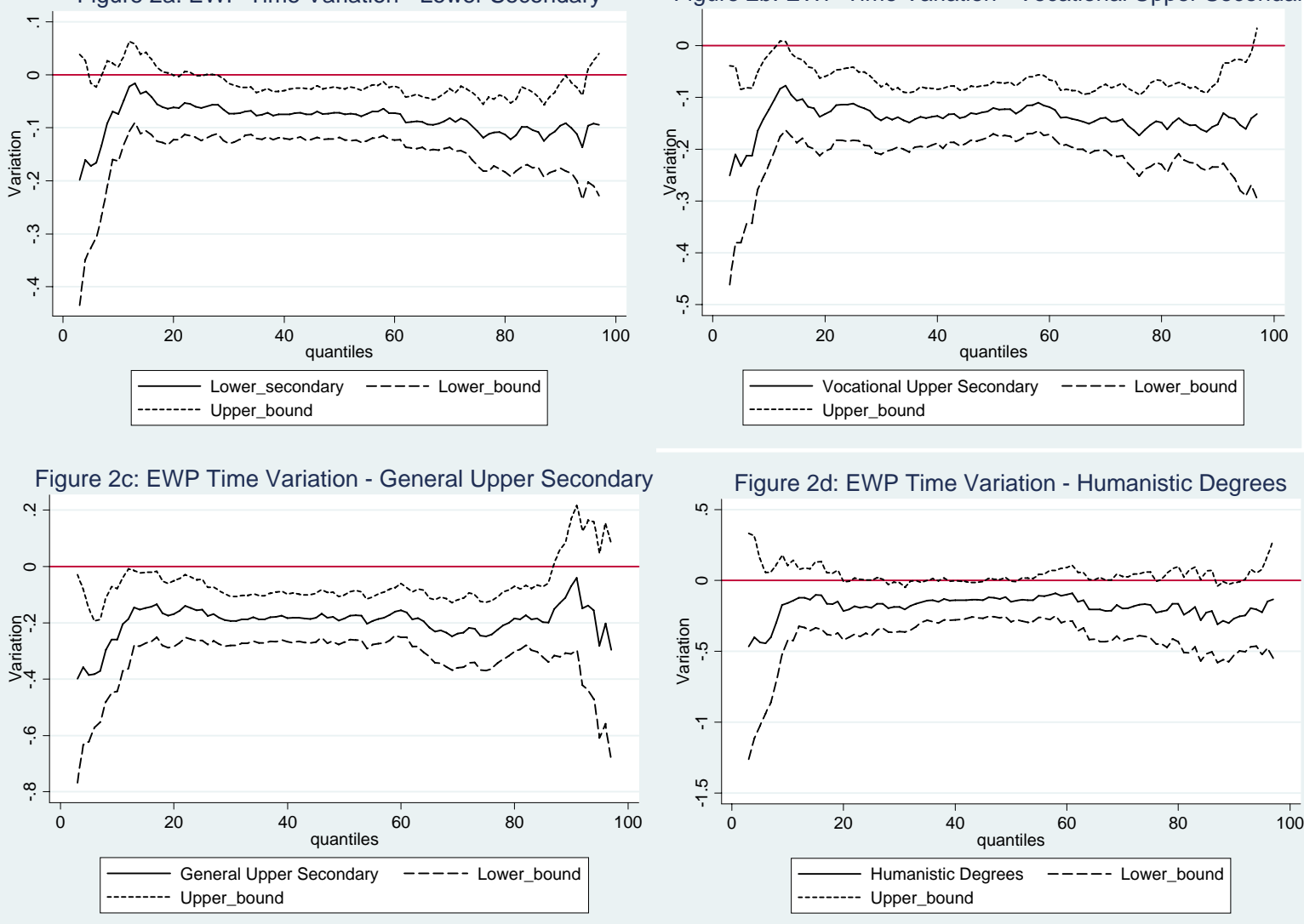

Figure 2d: EWP Time Variation - Humanistic Degrees

Figure 2e: EWP Time Variation - Professional Degrees

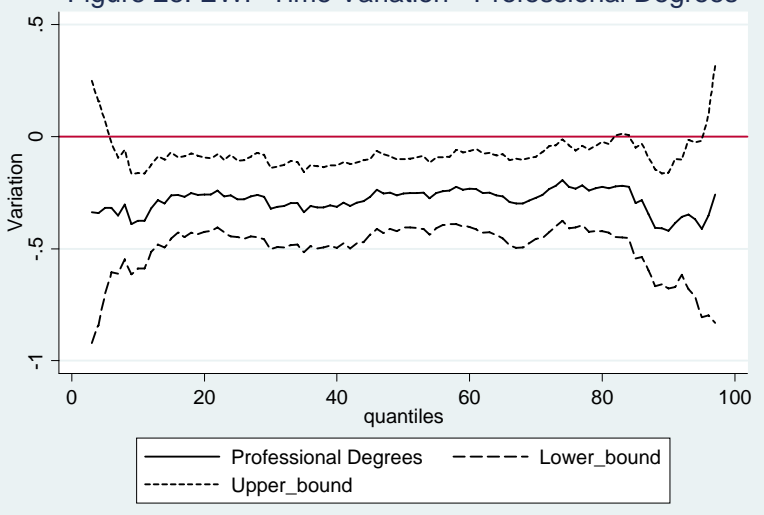

Figure 2f: EWP Time Variation - Scientific Degrees

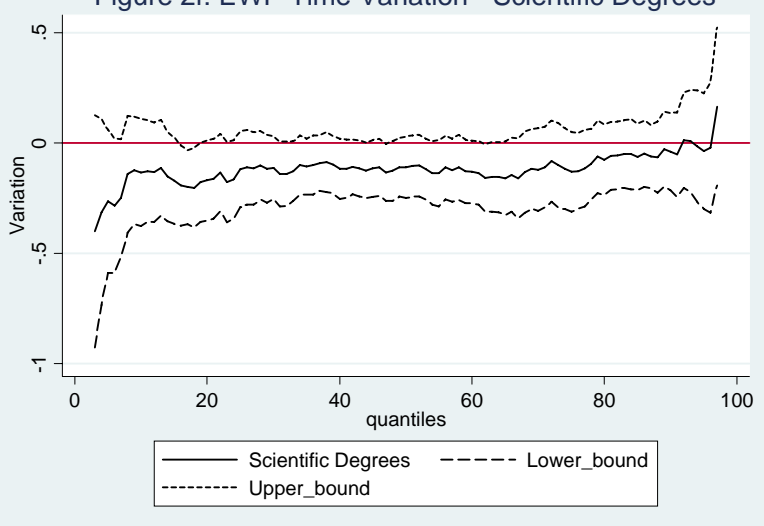


Table A1: SHIW Sample descriptives for variables used in the third column of table 6

\begin{tabular}{lcc} 
& $\mathbf{1 9 9 3}$ & $\mathbf{2 0 0 4}$ \\
\hline Age classes & & \\
15-24 & 0.15 & 0.09 \\
$25-30$ & 0.19 & 0.17 \\
$31-35$ & 0.14 & 0.14 \\
$36-40$ & 0.14 & 0.15 \\
$41-45$ & 0.13 & 0.14 \\
$46-50$ & 0.12 & 0.13 \\
51-55 & 0.09 & 0.11 \\
56-64 & 0.04 & 0.07 \\
\hline Type of industry & & \\
Agriculture & 0.05 & 0.05 \\
Manufactures, production and distribution of electric power, gas and & & \\
water & 0.46 & 0.41 \\
Building and construction & 0.09 & 0.10 \\
Wholesale and retail trade, & 0.16 & 0.18 \\
Transport, warehouse and storage and communication services & 0.06 & 0.07 \\
Services of credit and insurance institutions & 0.06 & 0.06 \\
Real estate and renting services, IT services, research, other & & \\
professional and business activities. & 0.05 & 0.06 \\
Domestic services provided to households and other private services & 0.07 & 0.06 \\
\hline Type of occupations & & \\
Blue-collar worker or similar & 0.59 & 0.56 \\
Office worker & 0.33 & 0.35 \\
School teacher in any type of school & 0.02 & 0.02 \\
Junior manager & 0.04 & 0.05 \\
Manager, senior official, headmaster, university. teacher, magistrate & 0.02 & 0.02 \\
\hline Firm size* & 3.54 & 3.18 \\
\hline Working hours & 39.79 & 38.80 \\
\hline Share of partime & 0.06 & 0.09 \\
\hline${ }^{*}$ Firm size is an average of a categorical variables, from 1 (the lowest) to 6 (the highest). & \\
& &
\end{tabular}

